\title{
Antecedents of situated learning in stressful service experiences: A cross-cultural study
}

Mousumi Bose Godbole

Fairfield University, mbosegodbole@fairfield.edu

Lei Ye

Follow this and additional works at: https://digitalcommons.fairfield.edu/business-facultypubs

Copyright 2013 Taylor \& Francis

The author post-print has been archived here with permission from the copyright holder.

"This is an Accepted Manuscript of an article published in Journal of International Consumer Marketing on 2013, available online: http://www.tandfonline.com/10.1080/

08961530.2013.803897."

\section{Peer Reviewed}

\section{Repository Citation}

Godbole, Mousumi Bose and Ye, Lei, "Antecedents of situated learning in stressful service experiences: A cross-cultural study" (2013). Business Faculty Publications. 178.

https://digitalcommons.fairfield.edu/business-facultypubs/178

\section{Published Citation}

Bose, Mousumi, and Lei Ye. "Antecedents of situated learning in stressful service experiences: A cross-cultural study." Journal of International Consumer Marketing 25.4 (2013): 219-233.

This item has been accepted for inclusion in DigitalCommons@Fairfield by an authorized administrator of DigitalCommons@Fairfield. It is brought to you by DigitalCommons@Fairfield with permission from the rightsholder(s) and is protected by copyright and/or related rights. You are free to use this item in any way that is permitted by the copyright and related rights legislation that applies to your use. For other uses, you need to obtain permission from the rights-holder(s) directly, unless additional rights are indicated by a Creative Commons license in the record and/or on the work itself. For more information, please contact digitalcommons@fairfield.edu. 


\title{
Antecedents of Situated Learning in Stressful Service Experiences: A Cross-Cultural Study
}

\begin{abstract}
Extant consumer behavior research has alluded to consumer learning; however, little research exists regarding situated learning and its antecedents with respect to stressful service experiences. Through this research, we qualitatively and quantitatively examine the topic of situated or in situ learning in two cultural contexts - that of U.S.A and China. Results demonstrate the importance of situated learning in dealing with stressful service encounters. Search for possibilities positively impacted situated learning for both U.S. and Chinese consumers. Unlike their U.S. counterparts, Chinese consumers initiated the process of learning long before experiencing the actual service, learnt more because of uncertainty of service standards and stressed on the importance of timely decision making as ways to learn and reduce stress. Interestingly, U.S. participants discussed the importance of empathy from service providers, trust and propensity for upfront feedback in enhancing learning. Theoretical and managerial implications are provided.
\end{abstract}

Keywords: Situated learning, dynamic learning, stressful service, cross-cultural 


\section{Antecedents of Situated Learning in Stressful Service Experiences: A Cross-Cultural Study}

As consumers, we are constantly learning from the environment. Whether it is learning about new product/service introductions, new uses of old products or adjustment of one's preference to fit the product/service into one's life, learning helps acquire purchase and consumption related knowledge and experience. Learning becomes even more important, especially when experiencing stressful situations. For example, when dealing with legal services related to divorce or computer repair services, consumers have to learn about the services and procedures involved, norms of the specific industry, firms, and perhaps about themselves in order to deal with the situation. Theories on problem solving and decision making rely on mechanisms of learning and adaptation (Simon, 1979) and as such, stressful service encounters may call for problem solving and learning. Thus, this research relates to consumers' in situ or situated learning when faced with stressful service encounters.

Situated learning refers to learning that takes place in the same context in which it is applied. Such emphasis on context suggests that situated learning is dynamic and is embedded within a particular social and physical environment (Lave and Wenger 1991). This learning is different from a static view of learning that is decontextualized, simplified and rigid. For example, a static view of learning would estimate a month for home repair to be completed after signing a contract with the services vendor. However, there may be unforeseen events (such as reliability of the service provider, consumer's urgency to complete the work on time, new regulations that need compliance and problems arising from the service process) that may stall or delay completion of the project. A static view of learning may not consider such unforeseen events and may not budget time and resources for these events. On the other hand, situated learning addresses the dynamic and changing nature of consumers' learning. Such learning 
incorporates environmental cues to constantly monitor the situation, learn from it, modify to suit the context and reduce the stress of going through the consumption process. Thus, by viewing learning as a process shaped by the transformations in the external environment, one can make more accurate estimations of solutions to a stressful service encounter. Besides, understanding consumer learning would be limited without the knowledge of the impact of environmental situations.

Understanding the influence of consumer situated learning can help marketers provide better customer service. The service industry constitutes about $80 \%$ of the U.S economy (Census of Service Industries 1999) and firms are facing ever increasing competition to better their standards. According to a Customer Dissatisfaction Study (2006), only six percent of customers who face a problem try to learn about solutions with some help from firms. Many struggle through the process of dealing with stressful service processes or service failures, and search for opportunities to switch or engage in negative word of mouth. While firms do employ various service recovery processes, little attention is allocated to understand the role of consumers as active learners and players in the service processes. By understanding how consumers learn in stressful service scenarios and the factors that affect such situated learning, firms can enhance their service delivery process to effectively deal with consumers' frustrations. Without engaging consumers in learning new knowledge and exposing them to the risks of poor self-performance in the process, firms may end up mismatching consumer's intrinsic needs and wants (Etgar 2008). Thus, helping enhance situated learning for consumers can go a long way in increasing consumer engagement and consumer repurchase intentions (e.g., Mittal and Kamakura 2001).

The goal of this paper is to understand situated learning in the context of stressful service encounters. Past research on situated learning has been limited to the field of education (Brown 
et al. 1989; Anderson et al. 1996; Kirk and McDonald 1998), psychology (Lave and Wenger 1991), sociology (McLellan 1996), organizational learning (Esterby-Smith et al. 1998) and webbased learning (Oliver and Herrington 2000) and very little is known about situated learning from a consumer's point of view. Given that customers are faced with stressful service episodes and they consistently learn to deal with it, discussions regarding situated learning are important for both marketing researchers and practitioners. Thus, this research explores the importance of situated learning and examines factors that affect situated learning in stressful service situations.

A second goal of this paper is to study situated learning in two cultural contexts. Learning styles and processes are considered to be different across cultures. Learning is based on concrete experience in an individualistic society while it is based on more abstract conceptualization for those in a collectivist society (Jaju, Kwak and Zinkhan 2003; Auyeung and Sands 1996). Additionally, Walsham (2001) has suggested that members of the collectivistic society are different in providing and sharing knowledge compared to the members of the individualistic culture. In collectivistic cultures, members tend to be willing to share their knowledge with other in-group members (Chow, Deng, and Ho 2000), while out-group information sharing for maximizing self-gains is more common amongst members of individualistic cultures (Earley 1989). Furthermore, culture has a strong impact on consumers' perceptions of service quality, and attempts made by firms to achieve universal service standards across cultures would be problematic (Donthu and Yoo 1998; Meng et al. 2009). As such, this study attempts to discover the commonalities and differences in antecedents that influence situated learning in an individualistic culture, the United States of America (USA) and a collective culture, China (Hofstede 1980a). 
The rest of the article is organized as follows: First, a brief literature review of situated learning is provided. This is followed by a brief outline of cultural differences between USA and China. Then, we present the methodology and results of two studies: qualitative in-depth interviews of consumers in the two cultural contexts that formed the basis for a survey based quantitative study of consumers who have experienced stressful service episodes. The paper concludes with a discussion, limitations of the study and future research directions.

\section{LITERATURE REVIEW}

\section{Situated Learning}

Situated learning (Lave 1988; Lave and Wenger 1991; Greeno, Smith and Moore 1992) emphasizes the idea that consumer knowledge is learned and applied in everyday situations. Learning essentially relates to creating meaning from the real activities of daily living. To situate learning means to place thought and action in a specific place and time, to involve other individuals, the environment, and the activities to create meaning (Lave and Wenger 1991). A situated learning experience has four major premises (Anderson, Reder, and Simon 1996; Wilson 1993): (1) learning is embedded in the actions of everyday situations; (2) knowledge is acquired from situations and transferred to other situations; (3) learning is the result of a social process encompassing ways of thinking, perceiving, problem solving, and interacting; and (4) learning is not separated from the situation but exists in robust social settings comprising of individuals, actions, and situations (Stein 1998).

Situated learning also encompasses cognition involving the cognitive schema. To understand situated learning, one must understand the role of schema interplaying with the situational variables to develop situated knowledge (Machles 2003). When faced with a new situation, consumers use their recollection of schemas on the new situation, framing it around 
what they already know. Consumers start with simplified schemas that become more complex as they continue to interact with the environment and learn. Thus, situated learning rather than situated cognition is important for consumers to handle stressful situations. Though both processes are interactive, situated cognition relates to thinking that is embedded in the context within which it occurs, while situated learning encompasses a broader range of knowledge accumulation and transfer. Moreover, situated learning is considered to have both cognitive and emotive components (Bose Godbole 2010). According to Gadanho (2004), both emotive and cognitive learning are important to understand the concept of learning as a whole. Additionally, situated cognition is momentary and temporarily bounded (Elbasch et al. 2005) whereas situated learning is not transient, resulting in long term accumulation and application of learning. Learning is stored and consumers bring out existing experiences from the schema and use them. Past research suggests that situated learning consists of four important elements: content, context, community of practice and participation (Lave 1988; Lave and Wenger 1991; Brown 1994; Choi and Hannafin 1995; Courtney, Speck and Holtorf 1996). Both content and context situated in consumer's experiences becomes the means to engage in thinking, interacting and gaining knowledge (Boud 1994; Shor 1996). Such situated content helps in the transfer of knowledge and its application in similar situations. Community provides the setting for the social interaction needed to engage in dialogue with others and participation provides the consumer with the meaning of the experience through attempts at problem solving, exchange of thoughts and dynamic engagement (Stein 1998).

While the concept of situated learning has been elaborated in the realms of education, psychology, sociology and anthropology, little research exists in the field of consumer behavior (Iyengar et al. 2007). Goel et al. (2010) have explained how the schema changes as a result of 
situated learning and suggested four dimensions of situated learning: thematic focus (focus on a common theme of learning), cognitive absorption (control, curiosity and focused attention as a result of intrinsic motivation), participation (engagement in social interaction) and social structure (pattern of relationships that develop between individuals as they relate to other members during a learning activity). However, their research pertains to the organizational context, which is different from consumption related stressful situations. Besides, there may be different aspects (e.g., importance of the learning process) that may be important for stressful consumption context compared to an organizational context. Thus, this gap in the consumer behavior literature warrants investigation and more importantly, it is essential to understand the factors that influence consumers to become active learners in problematic consumption situations. Moreover, it is important to understand how situated learning factors might be different in different cultural contexts, given the abundance of multinational firms using local strategies in global markets.

Past research has established that cultural contexts shape consumer learning experiences (Oxford 1996). For example, culture affects learning choice strategies: while consumers from individualistic societies may prefer more facilitative learning based on flexible strategies that are more concrete and active, consumers from collectivistic societies prefer more abstract and reflective use of analytic strategies aimed at precision and accuracy (Auyeung and Sands 2009). Additionally, consumers in collectivist societies have more in-group social preference, while those in individualist societies are more out-group and task-oriented (Hu and Jasper 2007). Meng et al. (2009) suggest that U.S. consumers are more likely to expect service providers to be efficient, while Chinese consumers are more likely to expect service providers to reduce their uncertainty by the guarantee of timely solutions to problems (Furrer et al. 2000). Hence, in 
understanding how situated learning in stressful service experiences differ in different cultural contexts, this research undertakes two studies each in an individualistic society (USA) and a collectivistic society (China). Since little research exists in explaining any similarities or differences in situated learning as well as its factors, we delved deeper into the topic by conducting in-depth interviews in USA and China. Such qualitative data collection helped us understand the emergent themes that formed the basis for survey-based quantitative research in a subsequent study.

\section{STUDY 1}

The aim of this study was to determine the nature of situated learning in an individualistic and a collectivistic cultural context represented by USA and China respectively. We chose these two contexts because the US has the highest individualism ranking with a score of 91, while China has been estimated to have a score of 20 , rendering the country to be considered collectivistic (Hostede 1981a). Services were considered to be stressful when consumers experienced anxiety in dealing with delivery failures or felt stress due to the prolonged nature of the process. Thus, interviews were conducted with consumers who had faced stressful service episodes that were both of short term and long term in nature. For example, airline ticket purchasing is considered to be a short term service, while dealing with lawyers related to divorce proceedings is considered a long term service. Inclusion of different types of stressful service encounters would provide meaningful insights to understand how consumers involve in situated learning from multiple perspectives. To maintain consistency in data collection, we interviewed those consumers who experienced a particular stressful service for the first time.

A total of thirty-six interviews were conducted, twenty of which were US consumers. Interviewees ranged from 21 to 70 years, with a mean age of 41 years. Most interviewees were 
from middle or upper middle class, with varied professions (corporate executives, housewives, nurses, copywriters and others). All interviews were semi-structured. The interviews lasted for half an hour to over an hour and were recorded, transcribed and analyzed. The data were coded using line-by-line coding at first and focused coding later (Charmaz 2006). The emergent themes were reviewed by a constant comparison method (Strauss and Corbin 1990) to determine the ones that became apparent across interviews.

\section{Results}

We first discuss situated learning in both cultures and then present the factors affecting situated learning that were found to be common and unique to the two cultural contexts.

\section{Situated Learning}

Interviewees from both cultures brought to light the importance of situated learning in dealing with stressful situations. The participants discussed how situated learning helped them deal with the service and the provider within a particular episode as well as helped them analyze and learn important lessons for subsequent episodes. The participants discussed the context, content, communication and participation in their situated experiences. As suggested in the quotation below, Sarah's situated learning related to service failure in an airline ticketing episode. She participated through understanding the situation and "keep fighting" with the firm to deal with the service failure.

"I knew about consumer tools like Better Business Bureau and bad publicity on the Internet, but I never considered actually using them against a company. I have never encountered SUCH incompetence. I realized that you have to keep at it. That's the biggest lesson - you have to fight with them, and keep fighting. Next time, if I am in a similar situation, I'll act sooner, if I have to. I think the repetition of it was the main learning experience - that you had to talk to different people about the same thing over and over and over again. And in the end the "art of arguing with -- (the firm)" was perfected."

While participants discussed situated learning from episodes of short term duration (such as service failure related to airline ticketing) mainly in terms of tactical performances, such 
learning was more complex for episodes of long term duration (such as facing stress related to divorce proceedings), sometimes involving elaborate information collection and analysis. For example, participants discussed their awareness and appreciation of the situation and the service provider, tactical efforts to gain information, making appropriate decisions in terms of what needs to be done and how things need to be done, execution of gained information and performance evaluation. Such elaborate learning processes helped further evaluate current situations for more learning and implementation.

"As I said earlier, every day is a new discovery. I used to have detailed discussion with my lawyer every day. I used to then sit back and analyze all the information, come up with the next set of queries and talk again the next day. So, each day's information and experience gave me new knowledge to ask better questions... And yes, it definitely made me calmer and more confident that I could get through the hassles...I also learned to stay away from silly mistakes."

It is apparent that cognitive absorption and participation are important components of situated learning. Such cognitive absorption and participation helped consumers realize what they were unaware of and needed to learn. This helped build a complex schema from a simplified one. We found that the Chinese consumers emphasized on the comprehensiveness of the process of situated learning. More than half of the Chinese participants described that learning started well before the actual initiation of transaction with the service provider. A host of activities are initiated as part of the learning process: researching alternative service providers, understanding the degree of stress involved in going through the service, and being prepared for the service process itself. Collectivists have been known to be long term oriented (Hofsede 1980a) and consider problems and their solutions from a long term perspective with a tendency towards holistic learning (Nisbett et al. 2001). Although participants in our study suggested that they made decisions in a timely manner when faced with uncertain service standards, they preferred to make decisions after taking different decision making parameters into consideration. Such 
decision making is different from that seen in individualistic cultures where consumers take more diagnostic view.

"It took me a long while and a lot of effort to have my house renovated. I just did not want to get into the process without knowing everything about the renovation process and the company. I waited months during which I learned as much as possible. I started to ask people about their experience of home renovation. I also bought a book about renovating my home. I read the book and downloaded tons of pictures from the Internet. I asked for samples and negotiated prices before I finalized my renovation company. I was in a better position to ensure they have the job done right. You never know what is there in store for the future. So, by learning everything about renovation, I could be in a position to negotiate better and made me stay calm and focused."

The above quotations also suggested the emotional aspect of situated learning - not only

did consumers learn about the cognitive and rational aspect of a situation and about themselves, they also realized the need to handle their emotional stress as well as ways to control it.

\section{Factors Affecting Situated Learning}

Two situational variables were found to enhance situated learning in both the cultural contexts, which are discussed first. Next, we discuss the trait based and attitudinal themes that are unique to U.S. and Chinese participants.

\section{Situational Themes Common to U.S. and Chinese Participants}

Empathy from service providers. Empathy relates to the identification and understanding of another's situation, feelings, and motives. It is the attribution of one's feelings to the object. Participants from both the individualist and collectivist cultures discussed whether the service provider had shown empathy towards them and had been responsive to their queries and requests. Participants emphasized the significance of empathy in enhancing interest in the firm and understanding and learning from the situation. Ian explained how empathy from his real estate agent helped increase his interest in working with the agent to reduce the stress of purchasing a home. Extant literature identifies empathy as a crucial player in the development of tolerance in client-agency relationship in advertising (Davies and Palihawadana, 2006). The greater the perception that the firm is interested in the welfare of the consumer, the greater is the 
interest of the consumer in working with the service provider to deal with a stressful

consumption experience.

"My real estate agent understood exactly what I was looking for when searching for a home. I remember, at one time, I was finding it hard to even express what I wanted but my agent was patient and did his best to understand me. So, when we were delayed in finding the right property, I was not frustrated but tried to understand what was going wrong. I even called to check with him and find homes myself to ease the stress for him and us."

Search for Possibilities. While firm-backed actions such as empathy helped enhanced situated learning, consumer-initiated actions also played a role. Participants discussed how the search for different solutions motivated them to learn more about the service provider, the situation and possible outlets of solutions to the problem at hand. As Anna waited for the tow truck after a road side accident, she checked for different options to avoid a four hour delay. She called the insurance company, the local towing agency and the local police to learn about the procedures that she had to follow subsequent to her accident. She also called her friends and family to gather their opinion about her predicament. Her openness to search for options helped her learn not only about the process and the ways service providers function but also about her own cognitive and emotional status during a stressful situation.

"Imagine waiting for four hours on a highway. It was not easy. I was frantic and kept thinking about my friends who could help and companies I needed to call. I do not know how many calls I made that day but all I did was to think of different ways to get out of the situation. Different people gave different ideas and slowly, I could figure out what was needed."

\section{Trait and Attitudinal Themes Unique to U.S. Participants}

Propensity for Upfront Feedback. U.S. participants appeared to be more forthright in providing criticisms whenever they encountered service difficulties. Most participants (75\%) perceived that such assessment would help service firms be aware of consumer difficulties and would help firms serve better. It would also help consumers voice their concerns (Hirschman 1970) to firms. The need for upfront feedback to firms propels consumers to learn about their service situation and even provide solutions when services are unfavorable. 
"I am always quick to find out how the service is and am openly critical of the company when I find inadequate services. I think I am benefiting them and myself and why not? It is important to say what you have in your mind. You are, after all, paying for it."

However, this was not a dominant theme amongst Chinese participants, who preferred to provide more indirect and guarded criticisms to save face of service providers (Chan et al. 2009).

Trust. All U.S. participants suggested that their trust of their service provider helped them learn more about the service providers to better deal with stress. Participants discussed various ways of trusting their service provider: whether it was by having confidence in the efficacy and ability of service providers or by relying on their advice to tide over unfavorable situations. Such reference of trust as an ingredient in situated learning has been found to exist in extant literature in terms of estimating the relationship quality (Lin and Ding, 2005; Sirdeshmukh et al. 2002).

"You know, if you do not trust your dentist, you will never want to use his services. That is a leap of faith you have to take. The more you have faith, [the more] you will listen to him and do what he says. That is one way to get better. And it is the same with any other service - the cable company for example. Every time there is a problem, I do what they tell me to do. And it works! It works!"

The Chinese participants, in contrast, discussed more of trusting their own efforts than the efforts of the service providers. Such hesitation in trusting the service provider may be owing to the perception of a lack of standardized service benchmarks in China. Besides, extant literature has suggested that propensity to trust out-group members is stronger amongst individualistic cultures like the United States while such inclination is lesser in collectivist societies like China (Huff and Kelley, 2003; 2005).

\section{Trait and Attitudinal Themes Unique to Chinese Participants}

Uncertainty avoidance. A dominant theme that emerged from Chinese participants dealt with the level of uncertainty that they perceived when availing services, especially since service standards may not be exceptional. Extant literature has discussed the importance of uncertainty avoidance in Asian cultures (e.g., Hofstede, 1981). Such uncertainty leads consumers to search and learn 
more about a particular situation before and during the service experience. We believe that the need to avoid uncertainty may drive the Chinese participants to be involved in the process of situated learning long before availing the service. Therefore, the greater need to avoid uncertainty resulted in greater levels of learning.

"You know, this is China. The service level is not as good as in U.S., and you expect that there will be problems and issues. If you want them to do what you want, it may or may not happen."

Propensity for Timely Decision Making. Although Chinese participants discussed the importance of taking different factors into consideration before availing the services of a provider, they expressed their anxiety in waiting for responses from service providers. The participants suggested that they were more likely to press on their service providers to solve their problems within the promised time frame. Most research has suggested that individuals from the collectivist society tend to take time in making decisions as they tend to weigh in all available information before finalizing on a decision. Our results indicate a different perspective on how Chinese consumers deal with service providers when they encounter stressful service situation. Such consumers tend to make decisions in a timely manner to help reduce their anxiety. This finding is consistent with Chinese consumers' high level of uncertainty avoidance. They need to feel that they have control when they deal with uncertain and stressful situations.

"When you deal with government sponsored service providers, you don't really have much choice. They are normally very bureaucratic; the best thing you can do is to know everything. That helps in immediately making decisions since you do not know how things will work out with them and whether you will get the service that you are really looking for."

In all, the qualitative study revealed a number of themes that discussed the antecedents of situated learning (Figure 1). Because these results are exploratory and not conclusive, a quantitative survey-based data was used to test the significance of the relationship between situated learning and its antecedents using both U.S. and Chinese samples. 
[Insert Figure 1 about here]

\section{STUDY 2}

The objective of Study 2 was to determine any differences in situated learning and its antecedents across individualistic and collectivistic cultures represented by USA and China respectively. Overall, our goal was to determine whether the relationships amongst themes that emerged from Study 1 would find support when tested quantitatively. The qualitative data suggested that culture played a role in influencing situated learning. Moreover, situated learning was found to be different in terms of its process with respect to the United States and China. The Chinese respondents appeared to take into account multiple factors and the learning process started much before they actually experienced the service episode. Finally, whereas there were some situational factors that enhanced learning for both USA and Chinese consumers, there were trait and attitudinal factors unique to each of the cultures that had a positive influence on situated learning. Specifically, empathy from service providers and the search for possibilities helped increase situated learning for consumers from both cultures. While the US consumers' propensity for direct and upfront feedback to the service providers as well as trust enhanced situated learning, the Chinese consumers revealed that uncertainty avoidance and the propensity to make timely decisions influenced their situated learning. Based on the summary of findings from Study 1, we formulated the following hypotheses:

H1: Culture positively affects situated learning.

H2: For members of the collectivist culture, the process of situated learning is more important than for those of the individualist culture.

H3: Empathy from service providers positively influenced situated learning for members of both individualistic and collectivistic cultures. 
H4: Search for possibilities influenced situated learning for members of both individualistic and collectivistic cultures.

H5: Propensity for upfront feedback enhanced situated learning for members of individualistic culture more than that for members of collectivistic culture.

H6: Trust on service providers enhanced situated learning for members of individualistic culture more than that for members of collectivistic culture.

H7: Uncertainty avoidance enhanced situated learning for members of collectivistic culture more than that for members of individualistic culture.

H8: Propensity for timely decision making enhanced situated learning for members of collectivistic culture more than that for members of individualistic culture.

This study used an online survey of nonstudent customers from U.S. and China to represent individualistic and collectivistic cultures. The questionnaire was pretested (with student sample) in both the countries to judge the unidimensionality and reliability of the constructs.

First, the context of the study was explained. Next, consumers were asked to explain the types of stressful services they experienced and rate their levels of stress. Then, they were asked to consider the most stressful service they had encountered, which created the context for subsequent construct measurements. The purpose of using consumer-revealed experience to study situated learning as opposed to creating a hypothetical situation was to allow real-life experiences to be the basis for data collection.

For the Chinese data collection, the questionnaire was forward-translated (Hambleton, 1993) to Chinese by two independent experts who were native speakers in Chinese. Next, the questionnaire was back-translated and retranslated for accuracy and consistency (Brislin, Lonner and Thorndike, 1973). After pretesting the scales, some further modifications were necessary as some words or phrases could not be exactly translated to Chinese (Brislin, 1980). Students from undergraduate marketing classes administered the survey to two identified consumers they knew 
who had experienced stressful service episodes, in lieu of class credit. Attention was paid to back check with the consumers who filled the survey.

\section{Sample and Measures}

The sample for this study comprised of a total of 318 (186 U.S. and 132 Chinese) participants. There were more female participants (61\%) than male participants $(39 \%)$. The mean age of U.S. participants was 41 while that of the Chinese participants was 51. All measurements in this study were adopted from extant literature (Table 1). Specifically, we modified items of situated learning based on the scale developed by Goel et al., (2010) to match the context of this study. Exploratory factor analysis revealed three factors - motivational situated learning, tactical situated learning and process based situated learning with reliabilities ranging from .80 to .89 . Hence, the items were summed for further analysis. Finally, possible multicollinearity problems among the independent variables were checked by inspecting the variable inflation factor and accompanying tolerance levels as well as the correlation matrix. In all instances, they were within the threshold level indicated by Hair et al. (1998); suggesting multicollinearity was not a problem.

[Insert Table 1 about here]

\section{Instrument validity}

When a measure is developed in one country and used in another, it is incumbent upon the researchers to ensure that the scales apply equally well and measure the same constructs in each culture (Berry, 1969). Even given the precautions we had taken to ensure questionnaire equivalence of meaning in the U.S. and Chinese culture, it was also important to be vigilant for response set bias. We did not find significance when tested for response set bias $\left(\mathrm{M}_{\mathrm{U} . \mathrm{S} .}=2.60\right.$, $\left.\mathrm{M}_{\text {China }}=2.50, F_{(1,294)}=2.75, p>.10\right)$. Next, we assessed construct equivalence across countries by 
comparing the factor loadings and reliabilities for each measure, following Singh (1995). Factor loadings were similar across countries. Reliabilities (measured by coefficient alpha) ranged from 0.75 to 0.89 for all multiple item constructs. Differences across countries were less than 0.05 in all cases, and are thus deemed acceptable (Nunnally \& Berstein, 1994, p. 264).

\section{Results}

Anova and regression were used to analyze the results. The first hypothesis helped determine whether culture affected situated learning. For this purpose, a regression that contained all the independent variables (empathy from service providers, search for possibilities, propensity for upfront feedback, trust, uncertainty avoidance and propensity for timely decision making) along with country (dummy coded: U.S.A. $=1$, China=2) was run on situated learning for the pooled dataset of U.S.A. and China. To ensure that demographic variables were controlled for, age and gender were used as covariates. As shown in Table 2, the results showed that the dummy variable coded for country was significant $\left(\beta=.21, t_{(270)}=4.56, p<.01\right)$, indicating important differences across the two cultures and necessitating an analysis of differences across the two cultures. Further, the homogeneity test or Chow test (Chow 1960) was used to further test if any differences existed between regression models across the two cultures. The test confirmed that the models were different from each other $(F=3.28, p<.05)$ allowing us to study the models for the individual cultures. Thus, H1 was supported.

The purpose of $\mathrm{H} 2$ was to find out whether significant differences exist in situated learning in the two cultural contexts. Results from an Anova analysis showed that U.S. and Chinese consumers differed in process based situated learning ('Going through the process increased my knowledge about service providers:' $M_{u . s .}=4.97, M_{\text {China }}=5.47, F_{(1,294)}=10.59$, $p<.01$; 'The process of learning helped me deal with service providers better:' $\mathrm{M}_{\mathrm{U} . \mathrm{s} .}=4.92$, 
$\left.\mathrm{M}_{\text {China }}=5.44, F_{(1,294)}=11.33, p<.01\right)$, with Chinese consumers more inclined to emphasize on the process than their U.S. counterparts, thus supporting our findings from Study 1. Thus, we find support for $\mathrm{H} 2$.

Hypotheses $\mathrm{H} 3$ to $\mathrm{H} 8$ determined the factors that enhanced situated learning across individualistic (U.S.A.) and collectivistic (China) cultures. We ran regression first on the pooled data and then on the data pertaining to each culture to determine the results (Table 2). Age and gender were used as covariates. The overall model for the pooled data was significant $\left(F_{(8,278)}=\right.$ $37.98, p<.01)$. It is interesting to note that more than fifty percent of the variance of situated learning was explained by the independent variables (adjusted $\mathrm{R}^{2}=.54$ ). As seen in Table 2, all independent variables except for propensity for timely decision making were significant. Next, individual regressions were run with culture as the selection variable. Results suggest that search for possibilities was a significant driver of situated learning for both the cultures $\left(\beta_{\text {U.S.A. }}=.25, p\right.$ $\left.<.00, \beta_{\text {China }}=.36, p<.01\right)$, thus supporting H4. However, empathy was significant for the U.S. sample $\left(\beta_{\text {U.S.A. }}=.20, p<.01\right)$ but not for the Chinese sample $\left(\beta_{\text {China }}=.12, p>.1\right)$, resulting in lack of support for H3. Both propensity for upfront feedback and trust were significant for U.S. consumers $\left(\beta_{\text {Propensity for upfront feedback }}=.22, p<.00, \beta_{\text {Service provider trust }}=.23, p<.00\right)$ but not significant for Chinese consumers $\left(\beta_{\text {Propensity for upfront feedback }}=.06, p>.1, \beta\right.$ Service provider trust $=.06, p$ $>$.1). The Chinese consumers suggested that uncertainty avoidance and propensity for timely decision making positively influenced their situated learning $\left(\beta_{\text {Uncertainty avoidance }}=.20, p<.00\right.$, $\left.\beta_{\text {Propensity for timely decision making }}=.22, p<.00\right)$. Although not predicted, we find that there is marginal significance for uncertainty avoidance in influencing situated learning amongst U.S. consumers $\left(\beta_{\text {Uncertainty avoidance }}=.10, p<.1\right)$. A test of the slopes for uncertainty avoidance for both countries demonstrated significance $(\mathrm{p}<.05)$, suggesting a higher level of uncertainty avoidance amongst 
Chinese participants compared to the U.S. participants. However, propensity for timely decision making did not have any influence on enhancing situated learning for the U.S. consumers $\left(\beta_{\text {Propensity for timely decision making }}=.00, p>.1\right)$. Thus, we find support for $\mathrm{H} 5, \mathrm{H} 6, \mathrm{H} 7$ and $\mathrm{H} 8$.

[Insert Table 2 about here]

\section{DISCUSSION}

The aim of this study was to understand the concept of situated learning in the face of stressful service consumption situations. The study was set in two cultural contexts to provide an understanding of the phenomenon and its antecedents. Much research underlines the steps that marketers should take when service situations are stressful owing to service failures. However, little research explores consumers' abilities to deal with stressful service situations by taking into consideration their learning processes and their applications. This research considers learning from a consumer's point of view, thus providing insights into different strategies and tactics that marketers can apply to reduce consumer stress. Additionally, this study uses actual consumers in both the qualitative and quantitative studies across both the cultures. Besides, data were collected in indigenous languages (English and Chinese). Such efforts were undertaken to do away with the problem of using student data and questionnaires designed to collect data from English speaking consumers (Meng et al 2009). Our results demonstrate that situated learning is indeed important for both cultural contexts. There are antecedents common to both cultures as well as unique ones that influence situated learning. Our results provide for interesting theoretical and managerial contributions.

\section{Theoretical contributions}

While experiencing stressful service episodes, consumers of both cultures used short and long term situated learning. Both qualitative and quantitative data revealed that consumers in 
collectivist culture emphasize learning more from the process itself than consumers in individualistic culture did. Extant literature from the field of education and learning also suggests emphasis on the process of learning (Cheng 2000) by Asian students in collectivist culture. This finding corroborates our results.

Our qualitative results pointed out that both firm and consumer initiated activities are important for consumer situated learning for both cultures: empathy from service providers offered the motivation and search for possibilities helped consumers learn and participate towards stress reduction. However, quantitative results demonstrated that though empathy contributed significantly to situated learning for members of the individualistic society, this was not the case for members of the collectivistic society. The results corroborate those suggested by Donthu and Yoo (1998) wherein expectation of empathy and attention is more characteristic of an individualistic society. The propensity for upfront feedback amongst individualistic consumers is in sharp contrast to collectivistic consumers who prefer not to provide immediate and upfront opinion. Opinions may be formed regarding the firm but providing feedback regarding the service or the provider is rare amongst collectivistic consumers. However, according to consumers from individualistic society, such feedback is important to receive better service and to learn more about the service and provider. Out-group trust is also a characteristic of individualistic society where many believe that trusting the firm would help better learn about the consumption problem and situation to cope better. Such out-group trusting is uncommon amongst collectivistic consumers. Finally, uncertainty avoidance and propensity for timely decision making were found to be characteristic of a collectivistic society like China. Although previous research had discussed superb service in Asian countries (Schütte and Ciarlante 1998), a majority of our Chinese respondents pointed out the lack of standardization as a major reason 
for wanting to gain more knowledge about the service and the provider in order to handle stressful service experiences. Such uncertainty may also create situations wherein consumers may find it obligatory to make timely decisions.

\section{Managerial contributions}

In the heterogeneous world of services, where processes and outcomes are often inconsistent and challenging, marketing managers need to understand the importance of situated learning of consumers. One aspect of providing excellent service relates to developing service delivery support system, which most companies strive towards. However, consumers are also a part of such a delivery system as they come into contact with the firm and its employees. In any service, consumers expend considerable time and effort to understand firm service levels, especially when they encounter stress related to service delivery. By understanding how consumers learn and the factors that affect their situated learning, managers can help consumers co-create or be part of the service process. A few industries practice such co-learning as a way of helping reduce consumer stress. For example, pilots offer flight related information in the face of delays or engine malfunctioning, while doctors tend to explain the process before and during any procedure. However, such consumer learning oriented processes are yet to be fully developed in many industries. Evans and Zou (2008) found that allowing customers to participate in service delivery enhances their satisfaction in service recovery processes.

Service providers should be cognizant of consumer efforts to learn and should willingly provide them with relevant information. Helping consumers learn better can signal the seriousness of the service provider's desire to better serve its customers by alleviating their stress and increasing their satisfaction. Participants of both cultures stressed the importance of search for possibilities during a stressful service experience. Such awareness can help marketers train 
their employees to frequently work with customers by informing them about different solutions to a service delivery issue and help deal with stress better.

This study suggests that consumers in different cultures take different approaches to learn and deal with stressful service encounters. To that end, service providers who operate in different cultures need to understand the cultural nuances and adjust their service deliberations and strategies to encourage situated learning. Assuming "business is business everywhere" will not hold any more. For consumers in collective culture, service firms need to reduce their uncertainty and facilitate situated learning by providing detailed information about the handling process and a guarantee to solve problems in a timely manner. For consumers in individualistic culture, eliciting feedback during unfavorable service episodes and working towards building trust would help with consumer stress reduction by empowering consumers to learn more from the situation.

\section{Limitations and Future Research}

Despite attention to the extant literature, methodology and analyses, limitations exist. While this study provides a natural context for data collection, research also needs to measure situated learning and its factors based on specific services applicable to individual cultures. Such an approach may reduce noise due to different service experiences to better compare results. Moreover, it is important to understand whether situated learning differs for short versus long term services. Additionally, it is essential to know whether the model would work for a one time situated learning experience compared to situations when the learning is applied to subsequent events. We speculate that learning would change over time as consumers acquire opportunities to elaborate on their past experience. We have provided a cross-sectional glimpse of situated learning. However, situated learning is a dynamic process of taking everyday knowledge and 
building on it based on situational experiences. Thus, it is important to study the phenomenon over time using longitudinal data to understand how simplified schema becomes more complex as consumers continue to gain and apply new knowledge.

Another limitation of this research relates to the context of situated learning. Contexts other than stressful service episodes need to be explored. Further, consequences of situated learning should also be studied to provide a holistic understanding of the situated learning process. Finally, various boundary conditions would need to be understood to completely understand the concept of situated learning. Elbasch, Barr and Hargadon (2005) have demonstrated the interactive effect of experience and other situational variables on situated learning. It would be interesting to understand how previous learning interacts with variables such as empathy from service providers, search for possibilities, etc. in influencing situated learning. Previous experience with service providers may heighten (or lessen) learning because of increased (decreased) sensitivity to perceptions of service providers. Hence, these nuances would be important to understand from theoretical and managerial perspectives.

In summary, the effect of situated learning in stressful services is an under researched area in marketing and further research will help demystify it. 


\section{REFERENCES}

Anderson, J. R., L. Reder, and H. A. Simon. 1996. Situated learning and education. Educational Researcher. 25 (4): 5-11.

Auyeung, P. K., and J. Sands. 2009. A cross cultural study of the learning styles of accounting students. Accounting and Finance. 36 (2):261-274.

Berry, J. W. 1969. On the cross-cultural comparability. International J Psychol 4: 119-128.

Bose Godbole, M. 2010. The role of situated learning in coping with stressful professional service experiences: An exploratory perspective. Journal of Retail Marketing Management Research 3 (2): 24-41.

Boud, D. 1994. Conceptualizing learning from experience: developing a model for facilitation. In proceedings of the thirty fifth annual adult education research conference, M. Hymans, J. Armstrong, and E. Anderson (Eds.). Knoxville: University of Tennessee. 49-54.

Brislin, R.W. 1980. Translation and content analysis of oral and written material. In H. Triandis, and J. Berry (Eds.). Handbook of cross-cultural psychology Boston: Allyn and Bacon. 1: 389444.

Brislin, R.W., W.J. Lonner, and R.M. Thorndike 1973. Cross-cultural research methods. New York: Wiley.

Brown, J.S., A. Collins, and P. Duguid. 1989. Situated cognition and the culture of learning. Educational Researcher 18 (1): 32-42.

Brown, A. L. 1994. The advancement of learning. Educational Researcher 23 (8): 4-12.

Burh, K, and m. J. Dugas. 2002. The intolerance of uncertainty scale: psychometric properties of the English version. Behaviour Research and Therapy 40: 931-945.

Charmaz, K. 2006. Constructing grounded theory: A practical guide through qualitative analysis. Sage Publications.

Chan H, L. C. Wan, and L. Sin. 2009. The contrasting effects of culture on consumer tolerance: Interpersonal face and impersonal fate. Journal of Consumer Research 36: 292-304.

Cheng, X. 2000. Asian students' reticence revisited. System 28 (3): 435-446.

Choi, J., and M. Hannafin. 1995. Situated cognition and learning environments: Roles, structures and implications for design. Educational Technology Research and Development 43 (2): 53-69. 
Chow, C. W., F. J. Deng, and J. L. Ho. 2000. The openness of knowledge sharing within organizations: A comparative study of the United States and The People's Republic of China. Journal of Management Accounting Research (12):65-95.

Courtney, S. S. Speck, and P. Holtorf. 1996. The impact of motivation, volition, and classroom context on adult learning. In Proceedings of the 15th annual midwest research-to-practice conference in adult, continuing, and community education Lincoln: University of Nebraska. 3539.

Cronin, J. J., and S. A. Taylor. 1992. Measuring service quality: A reexamination and extension. Journal of Marketing 56: 55-68.

Customer Dissatisfaction Study. 2006. Verde Baker Retail Initiative at Wharton, University of Pennsylvania, PA.

Davies, M. A. P., and D. Palihawadana. 2006. Developing a model of tolerance in client-agency relationships in advertising. International Journal of Advertising 25 (3): 381-408.

Dickerson, M. D., and J. W. Gentry. 1983. Characteristics of adopters and non-adopters of home computers. Journal of Consumer Research 10:225-235.

Dong, B. K. R. Evans, and S. Zou. 2008. The effects of customer participation in co-created service recovery. Journal of the Academy of Marketing Science. 36: 123-137.

Donthu, N., and B. Yoo. 1998. Cultural influence on service quality expectations. Journal of Services Research 1(2): 178-186.

Elbasch, K. D., P. S. Barr, and A. B. Hargadon. 2005. Identifying situated cognition in organizations. Organizational Science 16 (4): 422-33.

Easterby-Smith, M., M. Lyles, and E. Tsang. 2008. Interorganizational knowledge transfer: current themes and future prospects. Journal of Management Studies 45 (4): 677-690.

Etgar, M. 2008. A descriptive model of the consumer co-production process. Journal of the Academy of Marketing Science 36:97-108.

Furrer, O., B. S. Liu, and D. Sudharshan. 2000. The relationships between culture and service quality perception: Basis for cross-cultural market segmentation and resource allocation. Journal of Services Research 2(4): 355-371.

Gadanho, S. C. 2004. Learning behavior-selection by emotions and cognition in a multi-goal robot task. Journal of Machine Learning Research 5 (4): 385-412.

Goel, L., N. Johnson, I. Junglas, and B. Ives 2010. Situated learning: Conceptualization and measurement. Decision Sciences 8 (1): 215-240. 
Greeno, J. G., D. R. Smith and J. L. Moore. 1992. Transfer of situated learning. In D. Detterman and R. J. Sternberg (Eds.), Transfer on trial: Intelligence, cognition and instruction. 99-167. Norwood, NJ: Ablex.

Hair, J. F., R. L. Tatham, R. E. Anderson, and W. C. Black. 1998. Multivariate Data Analysis. $5^{\text {th }}$ Ed. Prentice Hall.

Hambleton, R. K. 1993. Translating achievement tests for use in cross-national studies. European Journal of Psychological Assessment 9: 57-68.

Handley, K., T. Clark, R. Fincham, and A. Sturdy. 2007. Researching situated learning: Participation, identity and practices in management consultancy. Management Learning. 38 (2): 173-191.

Hirschman, E. C. 1970. Exit, voice and loyalty: Responses to decline in firms, organizations and states. Cambridge, MA: Harvard University Press.

Hofstede, G. 1980a. Culture's consequences: International differences in work-related values. Beverly Hills, CA: Sage.

Hofstede, G. 1981. Cultures and Organizations: Software of the Mind McGraw Hill: UK.

Hu, H., and C. R. Jasper. 2007. A cross-cultural examination of the effects of social perceptions styles on store image formation. Journal of Business Research 60: 222-230.

Huff, L., and L. Kelley. 2003. Levels of organizational trust in individualist vs. collectivist societies: A seven-nation study. Organization Science 14 (1): 81-90.

Huff, L., and L. Kelley. 2005. Is collectivism a liability? The impact of culture on organizational trust and customer orientation: a seven-nation study. Journal of Business Research. 58 (1): $96-$ 102.

Iyengar, R., A. Ansari, and S. Gupta. 2007. A model of consumer learning for service quality and usage. Journal of Marketing Research. 44 (4): 529-544.

Jaju, A., H. Kwak and G. Zinkhan. 2002. Learning styles of undergraduate business students: a cross-cultural comparison between U.S., India and Korea. Marking Education Review.12:49-60.

Johnson, D., and K. Grayson. 2005. Cognitive and affective trust in service relationships. Journal of Business Research 58: 500-507.

Kirk, D., and D. MacDonald. 1998. Situated learning in physical education. Journal of Teaching in Physical Education 17 (3): 376-387. 
Lave, J. 1988. Cognition in practice: Mind, mathematics and culture in everyday life. New York: Cambridge University Press.

Lave, J., and E. Wenger. 1991. Situated Learning: Legitimate Peripheral Participation. Cambridge University Press, Cambridge.

Lin, C. P., and C. Ding. 2005. Opening the black box: Assessing the mediating mechanism of relationship quality and the moderating effects of prior experience in ISP services. International Journal of Service Industry Management 16 (1): 55-80.

Lumpkin, J. R., and W. R. Darden. 1982. Relating television preference viewing to shopping orientations, lifestyles and demographics. Journal of Advertising 11 (4): 56-67.

Machles, David (2003), "Training Situated Learning: New Approach to SH\&E Training Focuses on Learning," Professional Safety, (September), 22-28.

McLellan, H. 1996. Situated learning perspectives. Educational Technology.

Meng, Juan, J. H. Summery, N. C. Herndon and K. K. Kwong. (2009). some retail service quality expectations of Chinese shoppers. International Journal of Marketing Research 51(6): 773-795.

Mittal, V., and W. Kamakura. 2001. Satisfaction, repurchase intent and repurchase behavior: investigating the moderating effect of customer characteristics. Journal of Marketing Research 38 (2):131-142.

Moschis, G. P. 1981. Socialization perspectives and consumer behavior. In Review of Marketing (Eds. B. Enis and K. Roering). Chicago: American Marketing Association: 43-56.

Nidumolu, S., M. Subramani, and A. Aldrich. 2001. Situated learning and situated knowledge web: Exploring the ground beneath knowledge management. Journal of Management Informaiton Systems 18 (1): 115-150.

Nisbett, R.E., K. Peng, I. Choi, and A. Norenzayan. 2001. Culture and systems of thought: Holistic vs. analytic cognition. Psychological Review 108: 291-310.

Nunnally, J. C., and I. H. Berstein. 1994. Psychometric Theory (3rd ed.), Sydney: McGraw-Hill.

Oliver, R., and J. Herrington. 2000. Using situated learning as a design strategy for web-based learning. Instructional and cognitive impacts of web-based learning (Ed. B. Abbey). Idea Group Inc. 
Oxford, R. L. 1996. Why is culture important for language learning strategies? In language learning strategies around the world: Cross-cultural perspectives (Ed: R. Oxford). University of Hawaii Press.

Robey, D. M. C. Boudreau, and G. M. Rose. 2000. Information technology and organization learning: a review and assessment of research. Accounting, management and information technologies 10 (2): 125-155.

Schutte, H., and D. Ciarlante. (1998). Consumer behavior in Asia, New York University Press, Washington Square NY.

Simon, Herbert A. (1979), Models of Thought, Yale University Press, New Haven.

Singh, J. 1995. Measurement issues in cross cultural research. Journal of International Business Studies 3: 597-619.

Sirdeshmukh, D., J. Singh, and B. Sabol. 2002. Consumer trust, value and loyalty in relational exchanges. Journal of Marketing 66(1): 15-37.

Shor, I. 1987. Critical teaching and everyday life. Chicago: University of Chicago Press.

Stein, D. 1998. Situated learning in adult education. ERIC Clearinghouse on Adult Career and Vocational Education Columbus OH.

Strauss, A., and J. Corbin. 1990. Basics of Qualitative Research: Grounded Theory Procedures and Techniques. London: Sage.

Walsham, G. 2001. Making a world of difference: IT in a global context. Chichester: Wiley.

Wilson, A. 1993. The promise of situated cognition. In An update on adult learning theory. S. B. Merriam (Ed.). 71-79, San Francisco: Jossey-Bass. 
Table 1. Construct items and reliabilities

\begin{tabular}{|l|l|l|l|}
\hline Construct & Adapted from & $\begin{array}{l}\text { No. of } \\
\text { items/dimensions }\end{array}$ & Reliability \\
\hline Situated learning & Goel et al. (2010) & $12 / 3$ & $.80-.89$ \\
\hline Empathy from service providers & $\begin{array}{l}\text { Cronin and Taylor } \\
(1992)\end{array}$ & $4 / 1$ & .84 \\
\hline Search for possibilities & $\begin{array}{l}\text { Moschis (1981), } \\
\text { Dickerson and Gentry } \\
(1983)\end{array}$ & $4 / 1$ & .81 \\
\hline Propensity for upfront feedback & Developed & 1 & .85 \\
\hline Trust & $\begin{array}{l}\text { Johnson and Grayson } \\
(2005)\end{array}$ & $4 / 1$ & .88 \\
\hline Uncertainty avoidance & Buhr and Dugas (2002) & $3 / 1$ & .75 \\
\hline $\begin{array}{l}\text { Propensity for timely decision } \\
\text { making }\end{array}$ & $\begin{array}{l}\text { Lumpkin and Darden } \\
(1982)\end{array}$ & $3 / 1$ & \\
\hline
\end{tabular}


Table 2. Regression results for situated learning

\begin{tabular}{|l|c|c|c|}
\hline & U.S.A. & China & Pooled \\
\hline Main effects & & & \\
\hline Empathy from service providers & $.20^{* * *}$ & 0.12 & $.18^{* * *}$ \\
\hline Search for possibilities & $.25^{* * *}$ & $.36^{* * *}$ & $.30^{* * *}$ \\
\hline Propensity for upfront feedback & $.22^{* * *}$ & 0.06 & $.17^{* * *}$ \\
\hline Trust & $.23^{* * *}$ & 0.06 & $.20^{* * *}$ \\
\hline Uncertainty avoidance & $.10^{*}$ & $.20^{* *}$ & $.15^{* * *}$ \\
\hline Propensity for timely decision making & 0.00 & $.22^{* * *}$ & 0.05 \\
\hline & & & \\
\hline Dummy variable (country) & & & $.21^{* * *}$ \\
\hline & & & \\
\hline Covariates & & & \\
\hline Age & $.16^{* * *}$ & 0.05 & $.13^{* * *}$ \\
\hline Gender & 0.04 & $.11^{*}$ & 0.02 \\
\hline & & & \\
\hline F statistic & $24.85^{* * *}$ & $22.64^{* * *}$ & $37.98^{* * *}$ \\
\hline Adjusted R square (\%) & 0.51 & 0.63 & 0.54 \\
\hline Sample size (n) & 182 & 136 & 318 \\
\hline
\end{tabular}

$$
\begin{aligned}
& * * * p<.01 \\
& * * p<.05 \\
& * p<.10
\end{aligned}
$$




\section{Figure 1. Conceptual Model of Situated Learning}

Themes common

- Empathy
from
service

Themes common
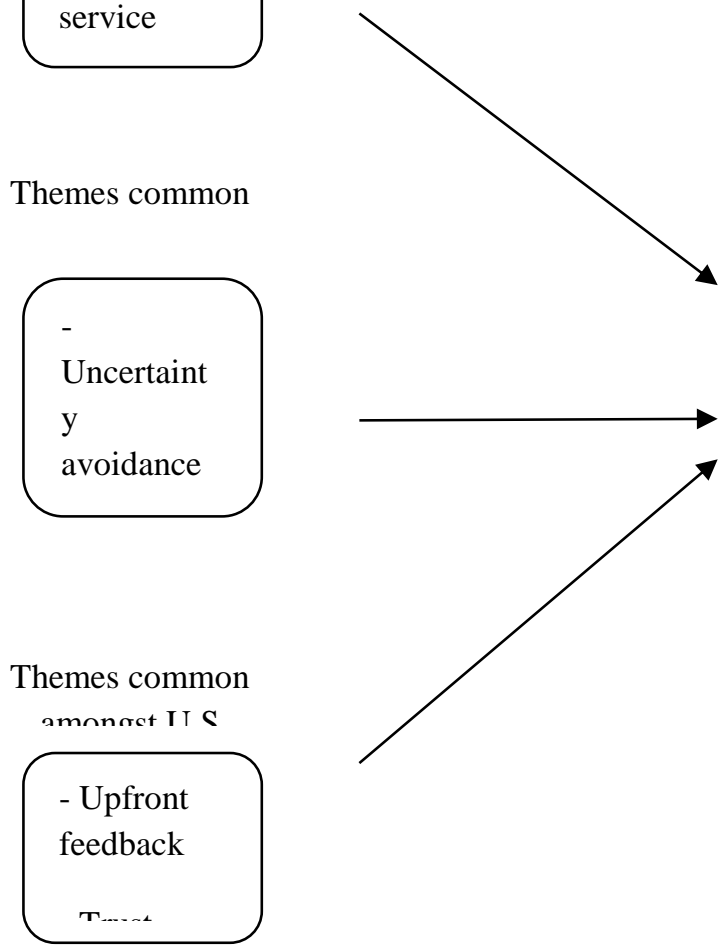

Situated
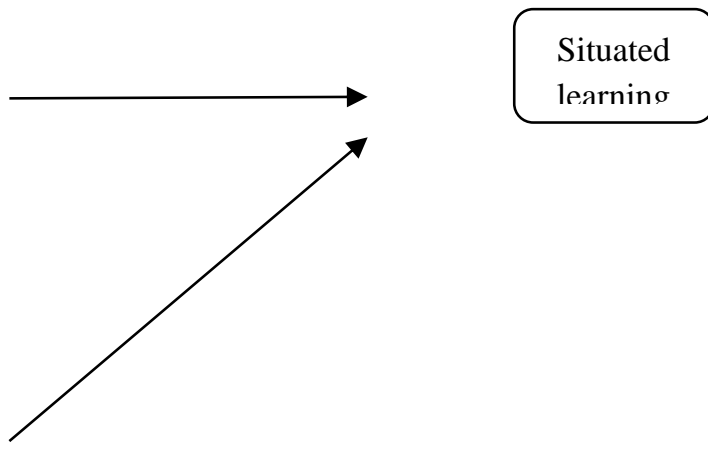